\title{
O conceito de cidadania a partir da obra de T. H. Marshall: conquista e concessão
}

\author{
The concept of citizenship from the works \\ of T. H. Marshall: conquest and concession
}

Josué MAstrodi

Pontifícia Universidade Católica de Campinas.

Campinas, São Paulo, Brasil

Ana Emília Cunha Avelar

Pontifícia Universidade Católica de Campinas.

Campinas, São Paulo, Brasil

Resumo O objetivo deste artigo é abordar discussões acerca do quadro teórico trazido por T. H. Marshall em sua obra Citizenship and Social Class. Analisaremos a relação feita pelo autor entre o desenvolvimento da cidadania e a concretização dos Direitos Fundamentais; o "surgimento" dos direitos civis, políticos e sociais, dispostos didaticamente ao longo dos séculos XVIII, XIX e XX. Pretendemos identificar a teoria de Marshall à compreensão da realidade inglesa e salientar algumas implicações a respeito da inadequação dessa análise ao contexto brasileiro.

Palavras-chave: T. H. Marshall. Cidadania. Direitos Fundamentais. Sociologia do Direito.

Abstract The purpose of this paper is to discuss on the theoretical scene brought by T. H. Marshall in his famous work Citizenship and Social Class. We seek to analyse the relations made by the author between the development of citizenship and the realisation of Fundamental Rights, the appearance of civil, political and social rights didactically established in the eighteenth, nineteenth and twentieth centuries. We intend to understand Marshall's theory as proper for the analysis of 
the English social reality and to emphasize some implications on the fact it cannot be adequately applied to the Brazilian context.

Key-words: T. H. Marshall. Citizenship. Fundamental Rights. SociOLOGY OF LAW.

\section{INTRODUÇÃO}

Thomas Humphrey Marshall, sociólogo britânico do início do século XX, desenvolveu em Citizenship and Social Class $^{1}$ a ideia de cidadania a partir do conjunto de três elementos de natureza normativa, uma parte civil, uma parte política e uma parte social. T. H. Marshall relaciona o desenvolvimento da cidadania ao desenvolvimento de cada um daqueles três de seus elementos, surgidos e afirmados cada qual em um século diferente: os direitos civis teriam se formado no século XVIII; os direitos políticos, no século XIX, e os direitos sociais, no século XX. A divisão é didática e, como adverte o próprio autor, ditada mais pela história que pela lógica (MARSHALL, 2002, p. 9). O autor considera que é por meio dessa construção histórica que se estabelece a ideia de cidadania.

A presente pesquisa visa identificar até que ponto podemos relacionar a formação dos direitos civis, políticos e sociais respectivamente com os séculos XVIII, XIX e XX, em especial se for levada em conta a realidade brasileira em vez da britânica.

Assim, em uma primeira etapa da pesquisa, tem-se a intenção de identificar as conexões de natureza social que permitem relacionar cada elemento da cidadania em uma dimensão sincronizada (LEANDRO, 2006, p. 2) aos eventos históricos de cada um dos séculos em que esses três elementos da cidadania de Marshall se desenvolveram com mais força. Em uma segunda parte da pesquisa, pretende-se relacionar o desenvolvimento da cidadania e sua influência sobre a desigualdade social e, por fim, almeja-se verificar a possibilidade de estender o desenvolvimento da cidadania, a partir da teoria de T. H. Marshall, para o contexto brasileiro.

Citizenship and Social Class foi publicado em 1950, fruto de uma conferência dedicada a Alfred Marshall no ano anterior. 
Consideramos que a evolução do conceito de cidadania dentro do contexto inglês fez-se de forma diversa dessa evolução na realidade brasileira, justamente pela diferença das condições históricas que deram margem à construção da cidadania nesses dois países.

A ideia de cidadania foi desenvolvida na Inglaterra antes mesmo da Revolução Industrial, quando já se fazia necessário afirmar e consolidar os direitos de uma forma mais abrangente, haja vista que o reconhecimento de direitos aos nobres, e posteriormente aos burgueses e até à classe trabalhadora, era essencial para a organização das relações de produção que se desenvolveriam a seguir e se tornariam próprias da Era Moderna. ${ }^{2}$ Em outras palavras, para o sucesso do novo modo de produção que se desenvolvia na Inglaterra, foi preciso que as pessoas se desprendessem da proteção feudal e passassem a comercializar bens, bem como, a própria força de trabalho, no mercado.

Já no Brasil, as condições históricas foram completamente diferentes: sua situação de colônia de exploração agrícola objetivamente impedia a evolução do senso de cidadania. A independência política de Portugal e, após a constituição de um império brasileiro, a consolidação de sua dependência econômica à Inglaterra, em aspecto relevante algum contribuiu para o desenvolvimento da compreensão de cidadania ou de direitos. ${ }^{3}$

2 “...contrariando o esquema marxista de interpretação histórica, pode-se dizer que, pelo menos na Grã-Bretanha, a revolução política criou condições para a revolução industrial do século seguinte, e não o contrário; ou seja, as revoluções sociais precederam e tornaram possível a transformação das forças produtivas" (COMPARATO, 2010 , p. 107). Não obstante, não foram os nobres nem a burguesia que implementaram subjetivamente a cidadania mas, objetivamente a necessidade econômica do novo modo de produção e organização social impunha o reconhecimento de direitos, necessários para o próprio desenvolvimento social e econômico.

3 A proclamação da República permitiu a modificação do poder político, no entanto os direitos civis eram compreendidos da mesma forma que antes, conforme as ordenações do reino (substituídas por normas jurídicas genuinamente brasileiras apenas em 1917, com a entrada em vigor do Código Civil); direitos políticos eram restritos por meios censitários que autorizavam a votação ativa e passiva apenas de uns poucos "cidadãos"; a quase inexistente industrialização e a reduzida população urbana contribuíam para a formação de um caldo de cultura em que sequer se compreendiam os direitos políticos ou, muito menos, os direitos sociais. 
Mesmo com a industrialização do início do século XX, a quantidade de momentos ditatoriais na política, a manutenção de uma estrutura econômica predominantemente rural, a falta de lutas sociais por direitos e a concessão de direitos para se evitarem eventuais conflitos sociais $^{4}$ não autorizam considerar que a cidadania, no Brasil, teria se desenvolvido na forma apresentada por Marshall. Nesse sentido, por decisão metodológica, tratamos o sentido de cidadania em Marshall em comparação com o conceito de cidadania no Brasil somente a partir da promulgação da atual Constituição Federal em 1988, momento de síntese da cidadania nacional, em que ao menos formalmente foram garantidas, no âmbito de um Estado Democrático de Direito, direitos civis, políticos e sociais a todos os membros de uma sociedade em cuja formação econômico-social predomina o modo capitalista de produção.

\section{Desenvolvimento da Cidadania dentro da Perspectiva de Marshall}

Foi no século XVIII que, na Europa ocidental, surgiram as condições históricas que levaram à conquista dos direitos civis, garantindo aos cidadãos - abstratamente, a todos os homens; concretamente, à classe burguesa - a capacidade jurídica de lutar pelos seus direitos, aqueles necessários à liberdade individual. Bem ressalta Marshall, que não se tratava da posse concreta desses direitos pelas pessoas, mas apenas da possibilidade de alcançá-los. ${ }^{5}$

4 Ressaltamos aqui a explicação de Vieira: "Verifica-se na História do Brasil que tivemos quase quarenta anos controlados por oligarquias civis quase antirrepublicanas, hostis à nação, ao Estado e à cidadania. Seguiram-se várias décadas de tutela militar. Assim, a vida política não conseguiria ser livre. Até a Revolução de 30, o modelo patrimonial de administração pública é predominante. Constata-se que a sociedade brasileira foi criada e desenvolvida sob o controle atento de um "Estado centralizador" e espoliado por uma elite patrimonial e burocrática que insiste por muito tempo em enriquecer e garantir os privilégios da exclusão da maioria” (VIEIRA, 2009, p. 11).

5 Na prática, os direitos civis só eram realidade palpável para o grupo social hegemônico, detentor do poder econômico e, desde as revoluções liberais, também do poder político. Para a manutenção da nova estrutura social que se estabelecia sobre 
Segundo Marshall, a consolidação desse primeiro grupo de direitos contribuiu para o surgimento, por volta do século XIX, dos chamados direitos políticos. De acordo com o ponto de vista desse autor, a participação política somente se estruturou na Inglaterra após a consolidação dos direitos civis. Nesse sentido, observou-se não só a criação de novos direitos a partir dos direitos políticos, como os direitos políticos permitiram a ampliação dos anteriores direitos civis a um maior contingente de pessoas, de forma a reparar uma antiga falha na compreensão da cidadania: sua falta de democracia. A esse novo elemento da cidadania corresponde, justamente, o direito de participar da vida política da sociedade, "começando do ponto no qual todos os homens eram livres, em teoria, capazes de gozar de direitos, a cidadania se desenvolveu pelo enriquecimento do conjunto de direitos de que eram capazes de gozar" (MARSHALL, 2002, p. 27). ${ }^{6}$

Por fim, os direitos sociais se referem ao direito a um mínimo de bem-estar social, e sua consolidação só seria alcançada quando todos os cidadãos tivessem acesso a esse mínimo. ${ }^{7}$ Os direitos sociais começaram a ser compreendidos com mais clareza na Europa do século

as ruínas da Idade Média e do antigo regime, era fundamental que a sociedade considerasse como justo o novo padrão liberal: direitos civis são atribuídos diretamente ao indivíduo, independentemente de seu estamento e de seus familiares, ao contrário das relações de colaboração próprias do feudalismo. Note-se que a liberdade como direito do homem é valor que já vinha sendo construído socialmente e descrito na literatura especializada, entre outros, por Bodin, Grotius, Locke, Bentham, Montesquieu, Kant e Rousseau.

6 Na verdade, a luta política entre burguesia e nobreza existiu justamente para, conforme a época e segundo a conformação de forças sociais, permitir ou impedir o avanço de direitos sobre as prerrogativas feudais da nobreza. Ora os burgueses afirmavam direitos naturais seus, ora os nobres tinham força para impedir essa afirmação. No início da era moderna, a conformação de forças sociais determinava que os direitos civis, inicialmente entendidos como direitos naturais a serem reconhecidos pelo Estado, cabiam exclusivamente aos burgueses e, posteriormente, tais direitos foram lentamente ampliados aos demais membros da sociedade por força desses novos direitos de participação política.

7 A cidadania em geral, e os direitos sociais em particular, nunca deixam de ser aprimorados. A efetividade da cidadania impõe a necessidade de se cumprir esse patamar mínimo de bem-estar social e de elevá-lo a condições cada vez mais consistentes. 
XIX, mas ainda eram vistos como casos de polícia e não de política. Os sindicatos eram entendidos pelos liberais muito mais como quadrilhas que aviltavam contra o bom instituto do contrato e que impediam a negociação das condições de emprego entre as duas únicas pessoas interessadas na contratação, o patrão e o empregado. A proteção ao trabalho (em especial contra acidentes dentro das fábricas, pensão por morte ou mutilação etc.) torna-se exigência dos trabalhadores, que passam a usar a arena política de tal modo que deixam de ser vistos como grupo de revoltosos para passarem a ser olhados como pessoas que lutavam por seus direitos. Ao relacionar os direitos sociais ao século XX, Marshall não tem qualquer intenção de ocultar essas condições históricas. Apenas se refere a uma condição específica dos direitos sociais de serem resolvidos, dentro do Estado, não por lutas ou por debates no âmbito do Poder Legislativo, mas por reivindicações políticas a serem acatadas pela Administração Pública. ${ }^{8}$

Cabe, aqui, uma distinção importante, para se evitarem confusões no âmbito da teoria dos direitos humanos. A teoria das gerações (ou dimensões) dos direitos não foi desenvolvida nos mesmos termos da perspectiva que Marshall elaborou seu entendimento sobre os três elementos da cidadania. De acordo com essa teoria das gerações ou dimensões, os direitos humanos (ou fundamentais) ${ }^{9}$ teriam tido sua afirmação histórica de modo a se identificarem segundo três momentos históricos distintos (gerações de direitos) ou três processos históricos de evolução (dimensões), cada uma relacionada a um dos valores do tríptico da Revolução

8 Em que pese não serem objeto do estudo de Marshall, ousamos incluir nessa relação os direitos sociais que o Estado de Bem-Estar Social (KEYNES, ROOSEVELT) passou a prover aos cidadãos, em especial por conta da necessidade de se evitar a quebra dos Estados liberais após o crash da Bolsa de Nova York, em 1929, e também do risco de revoluções visando ao ingresso no mundo comunista da então URSS.

9 Grosso modo, o que distingue os direitos humanos dos direitos fundamentais é a conformação dos últimos a um ordenamento jurídico de direito positivo, que lhes confere sentido preciso, com extensão e profundidade atribuídos pela estipulação de normas jurídicas. Não obstante, seu conteúdo decorre do conteúdo dos direitos humanos, cujo caráter é predominantemente moral. (A respeito da distinção, $c f$. KOERNER, 2003.) 
Francesa: liberdade, igualdade e fraternidade. Porém, conforme essa teoria de direitos humanos, os direitos de primeira dimensão são compostos tanto pelos direitos civis quanto pelos políticos; os direitos de segunda geração referem-se aos direitos sociais, e os de terceira geração, ao direitos difusos. Por sua vez, Marshall, que não escreveu sobre direitos difusos, distinguia os direitos sociais dos direitos civis e atribuía a estes precedência histórica e a qualidade de causa dos direitos políticos.

O quadro teórico sugerido por Marshall inicia-se no século XVIII, tomando como premissa que a dificuldade ${ }^{10}$ de outrora de se perceber e separar as funções estatais fazia que os direitos também fossem entendidos como se fundidos em um só (MARSHALL, 2002, p. 10). Os direitos não se distinguiam porque as instituições também não eram distintas.

A evolução da cidadania, na perspectiva do autor, "envolveu um processo duplo, de fusão e de separação. A fusão foi geográfica e a separação, funcional" (MARSHALL, 2002, p. 10). A ocorrência de um processo de separação, quando as instituições que abarcavam os três elementos da cidadania se separaram, tornou possível, para cada um desses elementos, "seguir um caminho próprio, viajando numa velocidade própria sob a direção de seus próprios princípios peculiares" (MARSHALL, 2002, p. 11); e, por conseguinte, um processo de fusão geográfica, ou seja, o nacionalismo das instituições não era mais o adequado a pertencer

10 Antes da era moderna, o poder (político, militar, econômico etc.) era concentrado em uma única pessoa ou estamento, não havendo espaço social para os plebeus sequer se reconhecerem como iguais aos detentores do poder. A partir do início da formação do Estado e das próprias funções estatais é que principiou o reconhecimento de tais direitos amparados em sua respectiva constituição. O Estado, no século XVIII, nem estava estruturado ainda, e sua construção se deu muito mais para proteger o modo de produção e garantir que os proprietários trocassem seus bens no mercado que qualquer coisa. A ideia era de um Estado que interviesse o mínimo possível na vida das pessoas, indivíduos livres e iguais que poderiam resolver tudo por conta própria. O Estado foi "posto" segundo uma estrutura que beneficiava o grupo social hegemônico e de modo que os demais grupos não teriam muita condição de modificar o seu funcionamento. Aliás, a ideologia da época apontava para a identificação de um Estado Racional, lógico e que não possuía falhas. Até as normas jurídicas que conferiam direitos civis a todos os homens eram tidas por conceitos lógicos e não pela emanação da vontade política de pessoas interessadas! 
à vida dos grupos sociais de caráter local. Foi com esse duplo processo, de fusão e separação, que os elementos que compõem a cidadania se confirmaram, tornando-se distintos entre si, e permitindo a Marshall, então, atribuir o período de formação de cada um de seus três elementos a um século diferente (MARSHALL, 2002, p. 12).

Não obstante, ressalte-se que o primeiro passo para o desenvolvimento da cidadania e a afirmação dos direitos civis se deu ainda no século XIII, com as primeiras manifestações contrárias à centralização do poder do Monarca por parte dos próprios senhores feudais, insatisfeitos com a estrutura jurídica da época, principalmente pela cobrança de impostos. $\mathrm{O}$ descontentamento com aquela política monárquica determinou a assinatura da Magna Carta, em 1215, pelo rei João Sem-Terra, uma imposição dos senhores feudais ao monarca, que já se encontrava enfraquecido devido às guerras externas, deixando "implícito pela primeira vez, na história política medieval, que o rei acha-se naturalmente vinculado pelas próprias leis que edita" (COMPARATO, 2010, p. 91 e 92). ${ }^{11}$

Em termos mais realistas, porém, a Magna Carta consistiu no reconhecimento de que o poder do monarca encontra limitações na força material dos estamentos livres (em especial da nobreza, mas também do clero), força pela qual se afirmaram direitos que passaram a existir independentemente do consentimento do rei.

Dentro da "dimensão sincronizada" (LEANDRO, 2006) elaborada por Marshall, Lea Guimarães Souki ainda afirma que o autor questionou, de forma implícita, "qual o grau de desigualdade compatível com os princípios da cidadania?” (SOUKI, 2006, p. 47) pois, partindo das ideias de Alfred Marshall, originárias de uma época em que os debates sobre a pobreza se intensificavam na esteira da "moralidade", criando-

11 Aliás, Comparato ressalta a importância da Magna Carta como embrião da democracia moderna: "A declaração final da primeira cláusula, segundo a qual o rei e seus descendentes garantiriam para sempre, a todos os homens livres do reino, as liberdades a seguir enumeradas, representou o primeiro passo para a superação oficial das divisões estamentais, pois o que conta doravante é, antes de tudo, o status libertatis, independentemente de qualquer outra condição pessoal" (COMPARATO, 2010, p. 92) 
-se uma distinção entre pobreza e indigência, a desigualdade entre os homens era tolerável desde que não os impedisse de serem "cavalheiros", assim significando:

Segundo Alfred Marshall, o constituir-se cavalheiro dependia da redução considerável do volume de trabalho pesado e excessivo que brutalizava a classe trabalhadora, e isto só ocorreria através do desenvolvimento da tecnologia (SOUKI, 2006, p. 50).

T. H. Marshall, continua Souki, "substitui cavalheiro por civilizado, reinterpreta a ideia de igualdade humana básica, latente no trabalho de A. Marshall, como cidadania, associando-a ao pertencimento pleno a uma comunidade cívica" (SOUKI, 2006, p. 50). A igualdade então passou a ser relacionada com cidadania, com o pertencer a uma comunidade, de forma que a desigualdade de classe seria aceitável desde que garantida a igualdade da cidadania dentro da comunidade a que o indivíduo pertencia. Ao citar Colquhoun, Marshall diferencia a "pobreza" da "indigência":

Por "pobreza", Colquhoun entendia a situação de um indivíduo que, devido à falta de quaisquer reservas econômicas, é obrigado a trabalhar, e a trabalhar muito, a fim de viver. Por "indigência", ele entendia a situação de uma família que se ressente do mínimo necessário para uma vida decente (MARSHALL, 2002, p. 26).

\section{SÉculo XVIII E diREITOS CIVIS}

Marshall adverte para a elasticidade que devemos tratar os períodos históricos, afirmando que o mais adequado ao desenvolvimento do elemento civil seria abranger "o período compreendido entre a Revolução [industrial] e o primeiro Reform Act” (MARSHALL, 2002, p. 12). Por meio do Direito Consuetudinário e da sua própria elasticidade ${ }^{12}$

12 "O Direito Consuetudinário era suficientemente elástico e permitia aos juízes aplicá-lo de uma maneira que, quase imperceptivelmente, levava em consideração as mudanças gradativas em circunstâncias e opinião" (MARSHALL, 2002, p. 13). 
no tempo, substituiu-se a premissa da intervenção governamental para garantir o direito de poucos, por uma nova suposição, pela qual certas restrições, ao ofender a liberdade do cidadão, também ameaçavam a prosperidade da nação. A mudança só ocorreu porque referida elasticidade permitiu aos juízes aplicarem aos casos concretos a nova visão de mundo que passava a predominar na sociedade, e assim, de forma gradativa, afastaram-se os costumes que impediam a mudança da estrutura vigente. Nas palavras do autor,

...quando o costume antigo no sentido técnico estava nitidamente em desacordo com o costume contemporâneo no sentido do modo de vida geralmente aceito, as defesas daquele começaram a ceder rapidamente ante os ataques do Direito Consuetudinário (...).a revogação das leis elisabetianas se deu prontamente como reconhecimento tardio de uma revolução que já havia ocorrido" (MARSHALL, 2002, p. 14).

É preciso ressaltar que tais desvios do direito consuetudinário mostravam o quanto as mudanças na estrutura econômica tendiam a garantir o novo padrão liberal de comportamento que, por sua vez, conferia legitimidade às mudanças na estrutura econômica. Marshall, citando Trevelyan, afirma que a tarefa inicial foi "o estabelecimento do reino do direito; e aquele direito, com todos os seus grandes erros, constituía, no mínimo, um direito de liberdade. Sobre aquela fundação sólida, construíram todas as reformas subsequentes" (MARSHALL, 2002, p. 12-13).

O elemento civil foi afirmado com base em uma pressuposição: a existência de um "status de liberdade": "na Inglaterra do século XVII todos os homens eram livres" (MARSHALL, 2002, p. 15). Fato que possibilitou Marshall concluir que os direitos civis se caracterizaram ao longo do século XVIII pela "adição gradativa de novos direitos a um 'status' já existente” (MARSHALL, 2002, p. 14).

Vale ressaltar, neste ponto, que o elemento civil possuía conotação muito mais ampla que a conferida pelo ordenamento jurídico brasileiro 
aos direitos civis. Muito mais que simples direitos voltados à proteção da propriedade e do contrato, os civil rights, no contexto inglês, vão muito além disso, tendo concepção análoga, no atual sistema constitucional brasileiro, à dos direitos fundamentais:

Direitos civis são os fundamentos à vida, à liberdade, à propriedade, à igualdade perante a lei. Podem ser compreendidos como a garantia de ir e vir, de optar por um trabalho, de expressar-se livremente, de não ser condenado sem processo legal regular. Direitos estes fundamentados em uma justiça independente, eficiente barata e acessível a todos, garantindo uma relação civilizada entre os indivíduos (CARVALHO, apud ANDRADE et al., 2011, p. 181).

Após a afirmação dos direitos civis no século XVIII, em que pese o avanço na compreensão de cidadania, ainda era possível encontrar restrições em vigor no âmbito econômico. Marshall exemplifica com o direito ao trabalho, que ainda reservava certas ocupações a determinados grupos sociais, proibindo-as para outros:

No setor econômico, o direito civil básico é o direito a trabalhar, isto é, o de seguir a ocupação de seu gosto no lugar de escolha, sujeito apenas à legítima exigência do treinamento técnico preliminar. Este direito tinha sido negado pelo costume; [...] e pelo uso do aprendizado como instrumento de exclusão ao invés de recrutamento (MARSHALL, 2002, p. 13).

O Direito ao trabalho livre precisou enfrentar o Direito Consuetudinário e as leis escritas, seu reconhecimento tratou-se de uma "nova suposição segundo a qual as restrições eram uma ofensa à liberdade do súdito e uma ameaça à prosperidade da nação" (MARSHALL, 2002, p. 13). 


\section{SÉculo XIX E direitos políticos}

O Parlamento inglês tem origem quando o rei Guilherme I instituiu um Conselho que analisaria e deliberaria leis e, por conseguinte, delimitaria o poder dos monarcas. Assim, pode-se dizer que a atuação política da monarquia na Inglaterra foi desde cedo limitada pelos seus súditos. ${ }^{13} \mathrm{~A}$ Declaração de Direitos (The Bill of Rights), datada de 1649, representou muito mais do que limitação do poder político: nas palavras de Comparato, pôs fim ao "regime de monarquia absoluta, no qual todo poder emana do Rei e em seu nome é exercido" (COMPARATO, 2010, p. 105).

Em que pese a formação do Parlamento, àquela época, ser composta em quase sua totalidade pela nobreza, a instituição estava constituída e a repartição do poder político do Estado, consolidada. A importância do Bill of Rights emana da "declaração de que o Parlamento é um órgão precipuamente encarregado de defender os súditos perante o Rei e cujo funcionamento não pode, pois, ficar sujeito a arbítrio deste" (COMPARATO, 2010, p. 108), ainda que o povo, o último estamento, não estivesse incluído nessa proteção.

Até o século XVIII, os direitos políticos não eram deficientes em conteúdo, mas sobretudo na sua distribuição (MARSHALL, 2002, p. 15). Em outras palavras, pode-se dizer que os direitos políticos não faziam parte do conceito de cidadania, ao contrário, tratava-se de um privilégio estritamente ligado ao status de cada pessoa, de forma que, de acordo com sua inserção a um ou outro estamento, deteria ou não essas prerrogativas.

Pode-se afirmar que, nesse momento histórico, que os direitos civis possuíam um caráter de universalidade, mas na prática eram estendidos apenas aos dois primeiros estamentos, enquanto os direitos políticos não eram sequer admitidos como formalmente universais. Os direitos políticos, então, referiam-se à mera capacidade de toda e qualquer pessoa, no sentido de que ela, com base em seu status, poderia

13 Aqui, como já exposto, tomamos como premissa que a promulgação da Magna Carta foi uma imposição dos estamentos livres ao monarca enfraquecido. 
exercer os direitos políticos possibilitados pelos direitos civis, de modo que eram os direitos civis que capacitavam os direitos políticos.

Parece que é próprio da sociedade capitalista tratar os direitos políticos como um produto secundário dos direitos civis, vez que o exercício dos direitos políticos dependeria de uma capacidade civil do interessado. Posição que começou a ser mitigada a partir de 1918, no fim da Primeira Guerra Mundial, quando se afirmou o direito de voto a todos os ingleses maiores de 21 anos de idade, e a todas as mulheres acima de 30 anos de idade: "pela adoção do sufrágio universal, transferiu a base dos direitos políticos do substrato econômico para o status pessoal" (MARSHALL, 2002, p. 16).

\section{SÉculo XX E DIREITOS SOCIAIS}

O autor descreve o desenvolvimento do elemento social com base nos acontecimentos ocorridos em âmbito da legislação trabalhista. Para Marshall, a participação popular nas comunidades locais e associações funcionais foi a fonte dos direitos sociais, tendo sido "complementada e progressivamente substituída por uma Poor Law" (MARSHALL, 2002, p. 17).

Dentro dessa perspectiva, Marshall aponta para a existência de uma visão ambígua da legislação trabalhista da época. Isso porque medidas protetivas tornaram-se incompatíveis com "a nova concepção de direitos civis na esfera econômica, com sua ênfase no direito de trabalhar ${ }^{14}$ onde e em que fosse do agrado do indivíduo e sob um contrato livremente estipulado" (MARSHALL, 2002, p. 17) pois, sob a ótica individualista do contrato de trabalho livre, pressupunha-se que, para que os trabalhadores conquistassem melhores condições nas fábricas, precisariam abrir mão de seus direitos como cidadãos, tanto os civis como os políticos. Dessa forma, os direitos sociais mínimos que resta-

14 "Este direito tinha sido negado pela lei e pelo costume; de um lado, pela Elizabethan Statute of Artificers, a qual destinava certas ocupações a certas classes sociais e, do outro, por regulamentos locais, que reservariam emprego numa cidade aos habitantes da cidade" (MARSHALL, 2002, p. 13). 
ram foram desvinculados do "status" de cidadania: a Poor Law tratava das reinvindicações dos pobres não como uma parte integrante de seus direitos de cidadão, mas como uma alternativa a eles (MARSHALL, 2002, p. 19).

Assim, é possível concordar com a afirmação pela qual "o esforço que havia sido feito não era o de eliminar a pobreza, mas sim seus efeitos desagradáveis" (SOUKI, 2006, p. 50), de forma que, segundo Marshall, foi apenas no final do século XIX que referidos argumentos contra medidas protetivas perderam força, de modo que o Estado passou a promover direitos sociais, a ponto de se considerar que o "código industrial se tornou um dos pilares do edifício de direitos sociais" (MARSHALL, 2002, p. 20), garantindo a partir das relações de trabalho, um mínimo de bem-estar social. Nas palavras de Souza, "a cidadania social representa a conquista de significativos direitos no domínio das relações de trabalho, da segurança social, da saúde, da educação e da habitação por parte das classes trabalhadoras" (SOUZA ICU, 2010, p. 450).

\section{Desenvolvimento do CONCEITO de CIDAdANia E SUA INFLU- ÊNCIA SOBRE A DESIGUALDADE SOCIAL}

Paralelamente ao quadro de desenvolvimento da cidadania, Marshall ainda expõe o impacto que a cidadania trouxe sobre as classes sociais, muito embora ele deixe claro que classe social é algo secundário em sua compreensão de cidadania. Para esta segunda análise, o autor novamente separa seu tema em períodos, antes e depois do final do século XIX, de acordo com a influência que o desenvolvimento da cidadania produziu na desigualdade social. Marshall inicia tal análise fazendo algumas considerações a respeito do impacto da cidadania acerca da desigualdade social em um primeiro período, e para tanto insere o conceito de "classe social".

"A cidadania é um status concedido àqueles que são membros integrais de uma comunidade" (MARSHALL, 2002, p. 24). Assim, em um sistema de medida de igualdade, todos aqueles que possuem o "status" também possuirão um mesmo conjunto de direitos e obrigações. "A clas- 
se social, por outro lado, é um sistema de desigualdade" (MARSHALL, 2002 , p. 24). Nesse sentido, o impacto da cidadania sobre a classe social torna-se "um conflito de princípios opostos" (MARSHALL, 2002, p. 24), pois o desenvolvimento da cidadania, dentro da perspectiva do autor, coincide com o desenvolvimento do modo capitalista de produção "que é o sistema não de igualdade, mas de desigualdade" (MARSHALL, 2010, p. 24). Esse questionamento leva Souza a concluir que "a todo momento a igualdade é invocada como um mantra poderoso que poderá solucionar os complexos dilemas sociais que decorrem do modelo de democracia existente" (SOUZA LC, 2010, p. 121).

A explicação para tal antagonismo de princípios que vigeram em uma mesma época encontra-se nos conceitos de "classe social" existentes entre a Idade Média e a Idade Moderna. Temos então, um tipo de classe social 15 como as camadas de um sistema hierárquico, que "divide uma sociedade numa série de espécies humanas distintas, hereditárias (...) uma instituição em seu próprio direito" (MARSHALL, 2002, p. 25), existente no período feudal, haja vista que o compartilhamento de algum grau de cidadania a todas as classes sociais inevitavelmente enfraqueceu o sistema hierárquico de classes.

Em um segundo tipo, mais voltado à análise dentro da Idade Moderna, classes sociais são encaradas em um sentido menos técnico, "elas emergem da combinação de uma variedade de fatores relacionados com as instituições da propriedade e educação e a estrutura da economia nacional" (MARSHALL, 2002, p. 25-26). É dentro desta segunda análise que o autor conclui a atual função da classe social: "considera-se a desigualdade social como necessária e proposital. Oferece o incentivo ao esforço e determina a distribuição de poder" (MARSHALL, 2002, p. 26). Entretanto, não havendo um padrão para um nível adequado de desigualdade, esta, embora necessária, poderia tornar-se excessiva, resultando não só na necessária pobreza, mas também na indigência, deplorada por Marshall: "o sistema de desigualdade que permitiu que a

15 Até a passagem para a Modernidade, apesar da terminologia utilizada por Marshall, devemos interpretar "classe social" como estamento. 
primeira existisse como uma força atuante produziu, inevitavelmente, uma dose da segunda" (MARSHALL, 2002, p. 26).

Foi ao tratar a riqueza como "prova conclusiva de mérito", e por conseguinte a pobreza como "prova de fracasso" que "os traços mais desagradáveis da desigualdade fossem tratados, de um modo um tanto irresponsável, como um incômodo". A diminuição da influência das classes sociais teria vindo com o despertar da consciência social, mas desde que "compatível com a eficiência continuada da máquina social" (MARSHALL, 2002, p. 27).

Aquele antagonismo de princípios então se extingue na medida em que se percebe que a cidadania, ao menos em seu ponto inicial, se formava agregando novos direitos ao conjunto de direitos a que todos eram capazes de gozar, não a posse efetiva desses direitos, de modo que a mera oportunidade de conquistar tais direitos não se contrapôs com a desigualdade da sociedade capitalista, "eram, ao contrário, necessários para a manutenção daquela determinada forma de desigualdade" (MARSHALL, 2002, p. 27). Exemplificado pelo direito a trabalhar, principal direito civil, núcleo da cidadania à época, que era encarado como prova do status de cidadão, ao se conferir o poder de participar do mercado competitivo, como uma unidade independente, e assim lutar pelos objetos que gostaria de possuir.

O termo 'todos', embora representasse uma proposta de universalização da cidadania como ainda não experimentada, ainda mantinha alguns critérios de exclusão de certos segmentos sociais que inviabilizavam a sua efetivação. [...] O cidadão moderno, portanto, era igual somente aos seus 'iguais' (SOUZA LC, 2010, p. 121-122).

No final do século XIX, percebeu-se que o mero reconhecimento da capacidade de obter direitos não era suficiente à concretização da cidadania. A manutenção dessa situação manteve-se por tanto tempo pela própria origem individualista dos direitos civis, que se harmonizavam com o individualismo do sistema capitalista. 
Para Marshall, os sindicatos fizeram que os trabalhadores pudessem exercer os direitos civis por meio de greves e dissídios coletivos, e estes direitos foram posteriormente utilizados como "instrumento para elevar seu status econômico e social, isto é, para firmar a reivindicação segundo a qual eles, como cidadãos, estavam habilitados a certos direitos sociais" (MARSHALL, 2002, p. 35). Porém, na concepção do autor, o método normal usado para se assegurarem os direitos sociais é pelo exercício dos direitos políticos, visto que dos últimos decorreria a concretização dos direitos civis e políticos ou, nas palavras do autor, "os direitos sociais pressupõem um direito absoluto a um determinado padrão de civilização que depende apenas do cumprimento das obrigações gerais da cidadania" (MARSHALL, 2002, p. 35).

Um aumento de rendas individuais distribuído entre as classes sociais também foi uma importante contribuição para o encurtamento da distância entre essas classes, assim os elementos da cidadania foram aos poucos distribuídos a muitos, até que "a diminuição da desigualdade fortaleceu a luta por sua abolição" (MARSHALL, 2002, p. 40).

O objetivo dos direitos sociais constitui ainda a redução das diferenças de classe, mas adquiriu um novo sentido. Não é mais a mera tentativa de eliminar o ônus evidente que representa a pobreza nos níveis mais baixos da sociedade. Assumiu o aspecto de ação modificando o padrão total da desigualdade social (MARSHALL, 2002, p. 40).

Já no século XX é possível identificar o Estado garantindo um mínimo de certos serviços essenciais. Trata-se de um limite mínimo, de forma que todo cidadão estaria livre e apto para superar esse limite.

\section{A evoluÇão do Conceito de Cidadania no Brasil}

Nossa análise da Cidadania em âmbito brasileiro tem seu foco na promulgação da Constituição Federal de 1988, apelidada de Constitui- 
ção cidadã. ${ }^{16}$ A partir de uma breve contextualização da época, é possível entender por que o Poder Constituinte Originário abrangeu aspectos tanto de ordem capitalista, com ênfase em direitos civis, quanto de ordem socialista, com foco em direitos sociais.

Após 21 anos de uma ditadura em campo nacional, havia sede por direitos civis e políticos. Ao mesmo tempo, o cenário internacional se encontrava imerso na Guerra Fria e o muro de Berlim ainda simbolizava a divisão geopolítica do mundo; em síntese, o socialismo ainda assustava o regime capitalista. Havia, assim, espaço para se exigir a positivação de certas demandas de caráter social.

O processo para o reconhecimento das demandas populares se deu pela possibilidade de reorganização de grupos políticos, partidos e sindicatos, pela retomada das greves trabalhistas e dos movimentos sociais, em suma, "foi o movimento pela redemocratização, iniciado em fins dos anos 1970, que retomou as pressões pelo restabelecimento da liberdade e dos direitos civis plenos" (BARROS e CARNEIRO, 2011, p. 37).

No decorrer dos anos de 1970 a 1980, os movimentos sociais pela redemocratização se diferenciaram dos anteriores, surgidos antes e logo após a eclosão do regime militar, em especial por suas origens, pois carregavam em seu bojo sua própria ideologia de resistência. Assim, cada uma das frentes sociais - os partidos políticos, os sindicatos, bem como, a igreja - cada qual em sua estrutura, "inauguram um outro modo de pensar e fazer política” (MONTEIRO et al., 2006, p. 10), enfatizando o cotidiano e implementando organizações nos bairros, nas fábricas e nas comunidades, em uma microdimensão jamais abrangida pelos movimentos sociais anteriores.

Como uma "estratégia coletiva de resistência" (MONTEIRO et al., 2006, p. 10), esse novo modo de pensar dos movimentos sociais, ao causar resultados positivos em microdimensões do cotidiano, fez que a luta pela redemocratização buscasse aspectos mais abrangentes, dentro de uma dimensão mais ampla, e para tanto a representação partidária foi

16 Denominação dada pelo então deputado Ulysses Guimarães na presidência da Assembleia Nacional Constituinte. 
o instrumento utilizado pelos movimentos de redemocratização na esfera política brasileira. Em outras palavras, acreditava-se que a experiência positiva trazida pelos movimentos sociais em microdimensões pudesse ser ampliada a macrodimensões por meio da representação partidária.

A ampliação de tais movimentos teve seu êxito inegável com a conquista de um Estado Democrático de Direito, fazendo-se acreditar que o novo modo de pensar e fazer política permitiria a manutenção, ampliação e universalização da cidadania. Entretanto, não se percebeu que referida conquista se dera pelo enfrentamento dos poderes ali estabelecidos, enquanto, nas palavras de Monteiro et al., "novos modos de dominação global se impunham numa versão mais sutil: a ditadura de mercado" (MONTEIRO et al., 2006, p. 10). A ideia de representação precisaria ser readequada para resistir a esse novo fator: em que pese o fato de que tais movimentos tenham trazido, e tragam até hoje, importantes aberturas democráticas, ao se desconsiderar a ditadura de mercado, desconsidera-se também a lógica dominador/dominado que sustenta o sistema capitalista. A ideia de representatividade política e de promoção da cidadania pela estrutura política cria a ilusão de que, ao se ocupar um lugar no poder político, possa-se usar esse poder de outra maneira, por exemplo, visando a novas conquistas sociais (MONTEIRO et al., 2006, p. 11). ${ }^{17}$

No auge dessas mudanças políticas, a promulgação da Constituição Federal, em 1988, é um marco na consolidação dos direitos humanos "no que se refere à maior participação da sociedade civil", possibilitando-se "condições para uma democracia participativa" (ANDRADE et al., 2012, p. 184). E é exatamente o fato das várias Constituições que já existiram no Brasil, tão diferentes em conteúdo, que fez Tavolaro concluir:

17 "Busca-se ocupar estes lugares de poder na suposição de poder assim possuir o poder. Ter poder, vontade de poder, vontade de dominar. Há ai uma ilusão de que se possa possuir o poder de Estado para usá-lo de uma outra maneira. Persiste aí a ideia de representação: vanguardas, salvadores, pastores identificados com a causa do bem maior, porque oriundos do lugar de dominados" (MONTEIRO et al., 2006, p. 11). 
Ao se respeitar essa lógica, casos como o da construção da cidadania no Brasil não parecem oferecer qualquer desafio analítico-interpretativo: os indisfarçáveis contrastes entre cada uma das constituições brasileiras revelam, de imediato, que aquela sequência sugerida por Marshall simplesmente não encontra a mais remota correspondência no muito pouco linear processo de institucionalização da normatividade moderna entre nós (TAVOLARO, 2001, p. 118).

Nossa Carta Magna demonstra o que Andrade et al., com base em José Murilo de Carvalho, salientam: no caso brasileiro, temos um processo histórico invertido em relação àquele descrito por Marshall na construção da cidadania na Inglaterra, de forma que "no Brasil, em primeiro lugar vieram os direitos sociais, em seguida os direitos políticos, e por fim os direitos civis" (ANDRADE et al., 2012, p. 186).

Ainda que voltemos a datas anteriores a 1988, e embora a lógica idealista defina que os direitos sociais são causados pelos direitos políticos, e estes pelos direitos sociais, essa lógica jamais determinou a formação histórica da cidadania no Brasil. Tais elementos da cidadania não foram implementados de uma forma ideal e satisfatória, caracterizando o que Andrade et al. vieram a chamar de "ausência de cultura cívica”, exemplificando tal aspecto pela Independência do Brasil, Proclamação da República e Revolução de 1930, movimentos que ocorreram sem uma revolução social ou política (ANDRADE et al., 2012), isto é, sem qualquer participação popular.

O fato de a participação da sociedade civil em seu aspecto político estar hoje garantida em lei não foi capaz de modificar seu caráter precário, de forma que a representação partidária perde espaço para uma cultura estatista e autoritária, em que o "o Estado sempre assumiu uma postura central na relação entre poder público e sociedade", o que faz enquadrar o Brasil, segundo a teoria de Carvalho, no rol dos países que "desenvolveram sua cidadania de cima pra baixo" (ANDRADE et al., 2012, p. 186).

Nesse mesmo sentido, "nota-se que há um predomínio de ações que conferem maior poder ao Estado, como responsável pela estrutu- 
ração e desenvolvimento da cidadania" (ANDRADE et al., 2012, p. 188). Referidos aspectos nos possibilitaram ouvir o quanto é necessário "implementar a cidadania", famoso jargão de nossos líderes políticos, demonstrando o que José Murilo de Carvalho vem a chamar de "estadania" (CARVALHO, 2002).

Para Carvalho, a cidadania no Brasil, de modo diferente da história de muitos países, não foi conquistada por revoluções, mas sempre por espécies de concessões do Estado à população, uma sequência de programas assistencialistas que implementam, pouco a pouco, direitos aos cidadãos. Andrade et al., apesar de sua concordância com o regime de estadania, nos mostram a possibilidade no avanço do progresso da cidadania por meio da criação de organizações não-governamentais e associações comunitárias, que passaram a tornar-se "um meio de diálogo entre a sociedade civil e o Estado" (ANDRADE et al., 2012, p. 185, 2012), ao assumirem funções que antes eram do Estado. ${ }^{18}$

Esse viés liberalista de redução do Estado teve seu auge durante os mandatos do presidente Fernando Henrique Cardoso, onde "observa-se uma preocupação em relação à modernização da administração pública" (ANDRADE et al., 2012, p. 188), de forma que a democratização passava a ocorrer por meio da participação das instituições privadas e do terceiro setor. Durante os mandatos de Luiz Inácio Lula da Silva, seguiram-se as ações de democratização da gestão estatal, ampliando a importância dos conselhos gestores e, por conseguinte, da participação dos cidadãos na política estatal.

18 Entendemos, não obstante, que a atuação crescente de entidades do terceiro setor na promoção dos mais variados interesses públicos e sociais acontece mais por conta da estrutura liberal de Estado, pela qual este é reduzido ao máximo, em especial pelo sucateamento das entidades da Administração Pública indireta. Surgem, assim, ONGS que buscam atuar no espaço social largado pelo Estado. A substituição do Estado pelas ONGS possui ao menos um problema. Como as ONGS visam especificamente à resolução dos problemas concretos, desprezam-se as questões relacionadas ao planejamento da promoção dos direitos sociais. 


\section{CONSIDERaÇões FINAIS}

As análises realizadas no quadro exposto por Marshall, relacionando a consolidação da cidadania ao desenvolvimento de cada um de seus elementos, nos permitiu trazer esta análise ao contexto brasileiro.

$\mathrm{O}$ sistema econômico industrial inglês precisou da força de trabalho nas fábricas e manufaturas para se manter: foi preciso tirar os antigos camponeses dos feudos e instalá-los nas indústrias, cumprindo pesadas jornadas de trabalho a fim de abastecer um mercado de bens em ascensão. O burguês, ainda que proprietário dos meios de produção, precisava da mão de obra de seus empregados para que a produção pudesse ser empreendida. E isso só foi possível com a afirmação dos direitos civis, pelos quais, a partir de uma igualdade formal, permitiram que empresário e empregado pudessem realizar um contrato em que ambos se reconhecessem iguais entre si e pudessem, pela autonomia de suas vontades, acertar as condições de trabalho. Foi o início da "conquista" da cidadania na Inglaterra industrial. Do mesmo modo, a ausência inicial de direitos políticos impedia o estabelecimento estatal de novos direitos civis e também de melhores condições de trabalho. A ausência de leis protetivas dos trabalhadores impedia a implantação de políticas públicas visando à promoção de direitos sociais.

Ao passo que, no contexto brasileiro pós-regime militar, o simples reconhecimento dos direitos civis e políticos não parecia o caminho mais efetivo na busca de uma cidadania plena. A abertura política deu força à concretização de demandas populares de pequenas esferas da sociedade, até então marginalizadas no campo social. O desenvolvimento de nossa cidadania iniciou-se muito mais pelo reconhecimento de que, sem direitos sociais, não haveria condições materiais para a construção dos direitos civis e políticos.

De modo diferente do caso inglês, a institucionalização no Brasil dos direitos sociais se deu na figura do próprio Estado, mediante governos que assumiram o papel central entre o poder político e a sociedade, configurando o que José Murilo de Carvalho denomina de "estadania". Assim, nossa precária cidadania está muito mais para uma forma de concessão do Poder Público do que uma conquista da sociedade civil. 


\section{REFERÊNCIAS}

ANDRADE, Daniela Meirelles Andrade; CASTRO, Carolina Lescura de Carvalho; PEREIRA, José Roberto. Cidadania ou "estadania" na gestão pública brasileira? Revista de Administração Pública. Rio de Janeiro, jan./ fev. 2011, p. 177-190. Disponível em http://dx.doi.org/10.1590/S003476122012000100009. Acesso em 14 de março de 2017.

BARROS, Douglas F.; CARNEIRO, Silvio. Revoluções e Direitos Humanos. Apostila do curso [s.1.], 2011.

CARVALHO, José Murilo de. Cidadania no Brasil, o longo caminho. Rio de Janeiro: Civilização Brasileira, 2002.

COMPARATO, Fábio Konder. A Afirmação Histórica dos Direitos Humanos, 7. ed. São Paulo: Saraiva, 2010.

KOERNER. Andrei. O Papel dos Direitos Humanos na Política Democrática: uma análise preliminar. Revista Brasileira de Ciências Sociais, v. 18, n. 53, 2003, p. 143158. Disponível em http://dx.doi.org/10.1590/S0102-69092003000300009. Acesso em 14 de março de 2017.

LEANDRO, Ariane Gontijo Lopes. Uma reflexão sobre a construção da cidadania a partir da experiência do Programa Mediação de Conflitos do Estado de Minas Gerais. Disponível em http://cpdoc.fgv.br/jornadadiscente/ trabalhos/Mesa_3_Claudio_Pinheiro_Ariane_Gontijo.pdf. Acesso em 14 de março de 2017.

MARSHALL, T. H. Citizenship and Social Class. In: MARSHALL, T. H. e BOTTOMORE, Tom. Citizenship and Social Class. Chicago: Pluto Classic (reimpr.), 1996, p. 3-51.

Cidadania e Classe Social [Ed. atual trad. e rev. Por EaD/CEE/MCT], 2. ed. Brasília: Senado Federal, Centro de Estudos Estratégicos, Ministério da Ciência e Tecnologia, 2002.

MONTEIRO, Ana Monteiro; COIMBRA, Cecília Coimbra; FILHO, Manoel Mendonça Filho. Estado Democrático de Direito e Políticas Públicas: Estatal é necessariamente público? Psicologia \& Sociedade, 18(2), mai./ago. 2002, p. 
7-12. Disponível em: http://www.scielo.br/pdf/psoc/v18n2/01.pdf. Acesso em 14 de março de 2017.

SOUKI, Lea Guimarães. A atualidade de T. H. Marshall no estudo da cidadania no Brasil. Civitas. Porto Alegre, v. 6, n. 1, jan./jun. 2006, p. 39-58. Disponível em http://revistaseletronicas.pucrs.br/ojs/index.php/civitas/article/ view/21/4848 Acesso em 14 de março de 2017.

SOUZA, Inês Cabral Ururahy de. Cidadania e Direitos Humanos no Estado Social e no Constitucionalismo Democrático. Pensar, Fortaleza, v. 15, n. 2, jul./dez. 2010, p. 442-454. Disponível em http://www.unifor.br/images/pdfs/ Pensar/v15n2_artigo6.pdf Acesso em 14 de março de 2017.

SOUZA, Luciana Cristina. A (Des) Proteção Normativa da Cidadania. Direitos Culturais, Santo Ângelo, v. 5, n. 9, jul./dez. 2010, p. 119-134. Disponível em http://srvapp2s.urisan.tche.br/seer/index.php/direitosculturais/article/ view/487/239 Acesso em 14 de março de 2017.

TAVOLARO, Sergio B. F. Quando discursos e oportunidades políticas se encontram. Para repensar a sociologia política da cidadania moderna. Novos Estud. -CEBRAP, n. 81, 2008, p. 117-136. Disponível em: http://dx.doi. org/10.1590/S0101-33002008000200010. Acesso em 14 de março de 2017.

VIEIRA, Rejane Esther. Democracia e políticas públicas: o novo enfoque da gestão pública na construção de espaços públicos de participação no Estado de Direito no Brasil. Direitos Fundamentais e Democracia, v. 6, 2009, p. 1-19. Disponível em: http://revistaeletronicardfd.unibrasil.com.br/index.php/rdfd/ article/viewFile/205/214. Acesso em 14 de março de 2017.

\section{SOBRE OS AUTORES}

\section{Josué Mastrodi}

Professor do programa de pós-graduação stricto sensu em Sustentabilidade e da faculdade de Direito da PUC-Campinas. Doutor em Direito pela USP.

CV: http://lattes.cnpq.br/6635472231072927

E-mail: mastrodi@puc-campinas.edu.br 
Ana Emília Cunha Avelar

Bacharel em Direito pela Pontifícia Universidade Católica de Campinas e Pós-graduanda em Direito Empresarial pela Fundação Getúlio Vargas. Advogada em Campinas.

CV: http://lattes.cnpq.br/6845900545437828

E-mail: anaavelar@hotmail.com

Submetido em: 19-05-2017

Aceito em: 28-11-2017 